\title{
The Assessment of Present, Past and Future Climate Variability in the Americas from Treeline Environments
}

Brian H. Luckman ${ }^{1}$ and José A. Boninsegna 2

1 Department of Geography, University of Western Ontario, London, Ontario, Canada, luckman@uwo.ca

2 Laboratorio de Dendrocronologia, IANIGLA-CONICET, Mendoza, Argentina, pbonin@lab.cricyt.edu.ar

In this note we introduce one of 14 Collaborative Research Networks (CRN) funded by the Inter-American Institute for Global Change Research. It was established in 1999 and involves 15 principal investigators from 13 institutions in Canada, USA, Mexico, Bolivia, Chile and Argentina. The primary goals of the project are (i) to develop a network of tree-ring chronologies from climatically-sensitive treeline sites in the western American Cordillera and (ii) to use these data to reconstruct and compare regional interannual to decadal climate variability along the PEP-1 transect from Alaska to Tierra del Fuego. The project also seeks to enhance the development and utilization of dendrochronology for tropical mountain tree species and expand collaboration, training and the application of paleoenvironmental science within Latin America to address the issues of climate variability and change.

\section{The existing Chronology}

The existing tree ring chronology coverage of the American Cordillera is patchy (see Fig. 1) and the initial sampling has targeted significant geographical gaps and key areas. We anticipate that the development of this more comprehensive geographical coverage will allow the reconstruction of spatial and temporal patterns of temperature and precipitation along this transect over the last several hundred years. Documentation of these changing spatial patterns is key to understanding the controls of climate variability. Several new chronology networks have been developed since the inception of the project. In the Southern Canadian Cordillera three new single species chronology networks have been developed for temperature reconstructions at upper treeline sites. A complementary network of 53 lower treeline moisture-sensitive sites has also been assembled and is being used to derive maps of annual precipitation anomalies and to assess drought frequency and intensity for the region over the last 300 years. Extensive sampling is also planned for temperature reconstructions from treeline sites across northern British Columbia and the Yukon in the next few years. In Mexico the new sampling programs have primarily targeted Douglas Fir and Montezuma Bald cypress stands across central and Northern Mexico to develop precipitation and drought reconstructions that have obvious applications to agriculture and forestry in addition to their paleoclimate significance. In South America, Nothofagus pumilo (lenga) dominates treeline sites in the southern Andes of Chile and Argentina. A network of over 90 lenga sites between $35^{\circ}$ and $55^{\circ} \mathrm{S}$ has been used to develop reconstructions of annual temperatures for northwestern and southern Patagonia between AD 1630 and 1987. Both reconstructions reveal the unusual nature of regional climate conditions during the 20th century when compared with the past 400 years. New chronologies have also been developed for Austrocedrus chil-

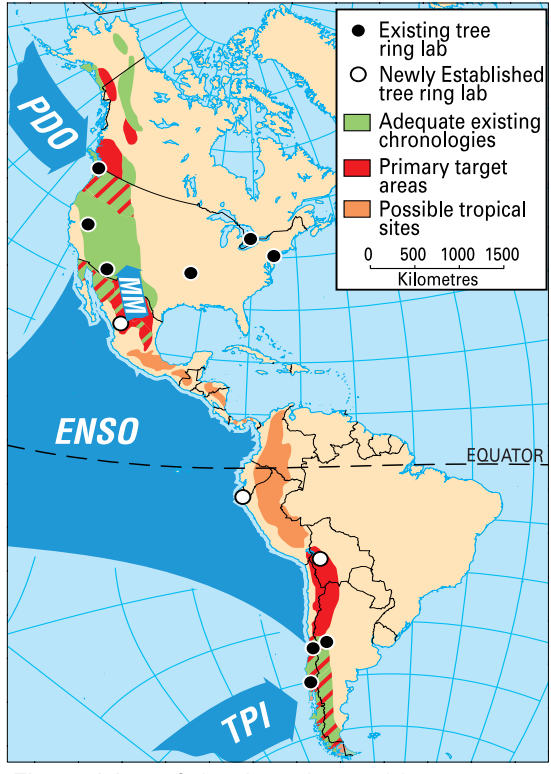

Fig. 1: Map of the Americas with prospective sampling areas and location of participating tree-ring laboratories.

(MM= Mexican Monsoon; TPl= Trans-Polar Index; $P D O=$ Pacific Decadal Oscillation)

ensis in both Chile and Argentina with a maximum length of over 1800 years that will yield long precipitation and ENSO reconstructions. Tree growth in many of these tree-ring series is strongly correlated with sea surface temperatures (SST) in adjacent areas of the Pacific and Atlantic Oceans (Fig. 2). Reconstructing the spatial and temporal variability of Pacific SSTs will

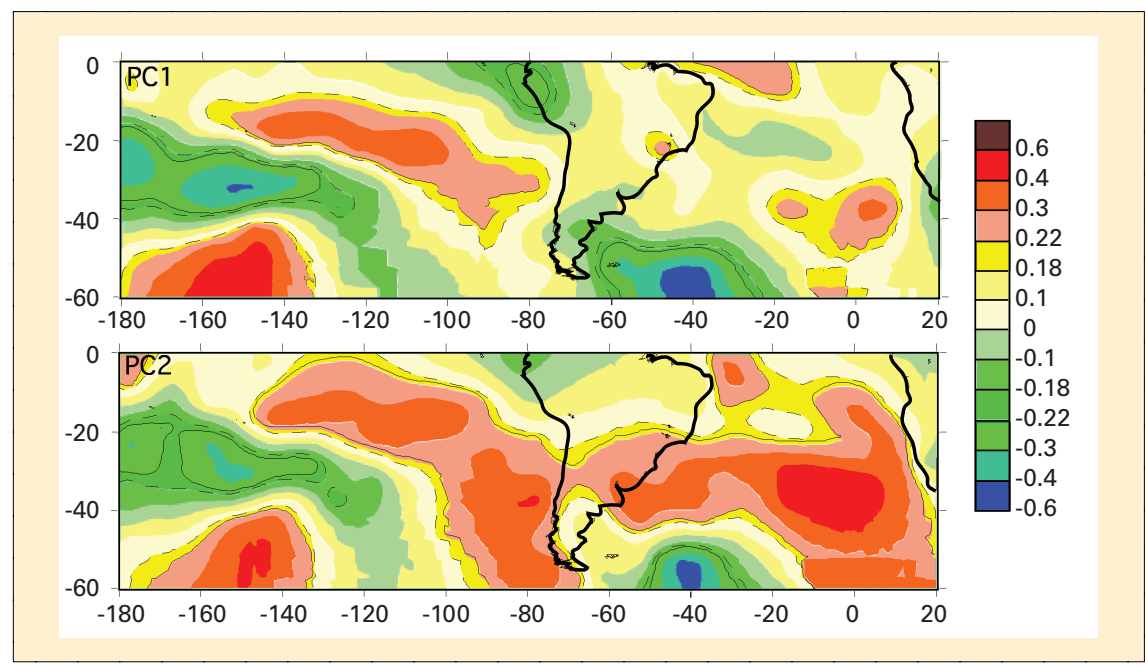

Fig. 2: Correlation fields between reconstructed temperatures in NW (above) and Southern Patagonia (below), based on lenga tree-ring width chronologies and SSTs across the South Pacific and South Atlantic. 


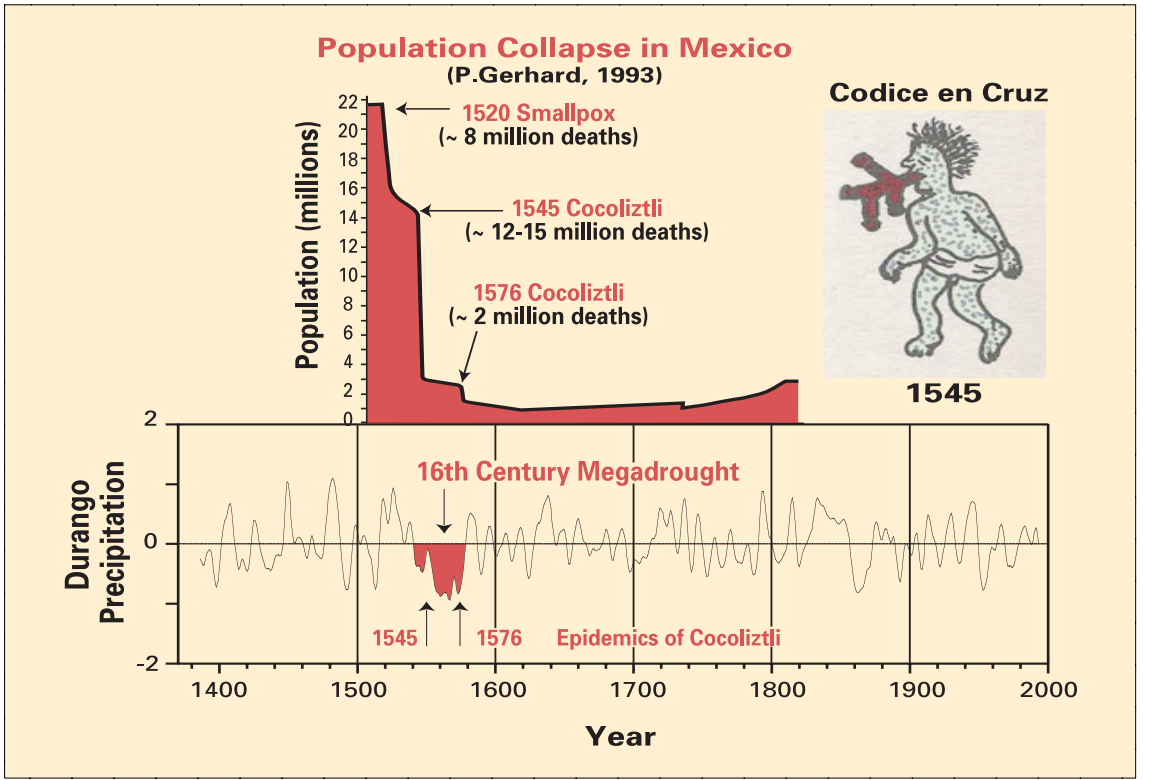

Fig. 3: Relationships between drought and disease in $16^{\text {th }}$ century Mexico (after Acuna-Soto et al., in press). The drawing is reproduced from contemporaneous sources.

enhance our understanding of the global climate system (e.g. in studies of EI Niño, PDO and their interrelationships). In conjunction with ongoing dendroclimate work, several investigators are also using dendrochronology to date glacier fluctuations of the last millennium in Canada, Chile and Argentina.

\section{The Mexican "Megadeath"}

In addition to their value as paleorecords, these tree-ring archives will also be applied to the study of a number of economic, social or environmental issues. For example, recent drought reconstructions indicate that the catastrophic cocoliztli epidemics of the Mexican Highlands beginning in 1545 and 1576 coincided with the most severe drought in the last 500 years (Acuna-Soto et al., 2000, Fig. 3). Cocoliztli is now thought to be an indigenous haemorrhagic fever, possibly transmitted by rodent hosts and aggravated by drought conditions. It is hypothesized that drought periods can concentrate and spread infection among the residual rodent population. When climatic conditions ameliorate, the infected rodent population may invade farms and homes to spread the disease agent. Humans infected with cocoliztli often died painfully in as little as 3-4 days. Similar climate forcing was observed during the Hantavirus outbreaks in the south- western US in 1993, but cocoliztli probably was not a Hantavirus and the true disease agent remains unknown. Nevertheless, the $16^{\text {th }}$ century epidemics do seem to have occurred during one of the worst Mexican droughts in the past 500 years, and the epidemics of 1545-8 and 1576-8 each reduced the population of the Mexican Highlands by about $50 \%$. Population recovery was slow and numbers remained well below their $16^{\text {th }}$ century levels until the $20^{\text {th }}$ century.

\section{Climate variability}

Reconstruction of climate variability in low latitudes has been hampered by the lack of suitable annually-resolved proxy climate records. This project attempts to narrow the "latitudinal gap" between the presently available tree-ring chronology networks by (i) expanding existing chronology networks equatorwards for those species known to have annual rings and (ii) by exploring the potential of many new species to yield annual ring series. During the last year we have developed chronologies from sites at the extreme range of Douglas fir (Pseudotsuga menziesii) at $17^{\circ}$ and $55^{\circ} \mathrm{N}$ in Mexico and British Columbia, respectively. Chronologies have also been developed from four new tropical species; Pinus hartwegii growing at 3,600-3,700m on Nevado de Colima volcano, Mexico $\left(20^{\circ} \mathrm{N}\right)$ : Polyl- epis tarapacana at 4,800-4,900m on Volcan Sajama, Bolivia $\left(18^{\circ} \mathrm{S}\right)$ and $4,750 \mathrm{~m}$ on Cerro Granados, Argentina $\left(22^{\circ} 32^{\prime} \mathrm{S}\right)$; Polylepis pepei in the Cordillera Tunari, Bolivia $\left(17^{\circ} \mathrm{S}\right)$ and Prosopis ferox at $3,500 \mathrm{~m}$ in the Humahuaca Valley, Argentina $\left(23^{\circ} \mathrm{S}\right)$. Although ring definition varies between these species they all show promise for the reconstruction of temperature (Polylepis) or precipitation (Pinus and Prosopis). Living specimens of Polylepis and Prosopis are known to reach ca. 500 years of age. The two Bolivian chronologies are the highest elevation tree-ring chronologies in the world.

\section{Future goals}

Expanding scientific capacity, training and exchanges are also major goals of the project. New laboratories have been established for basic dendrochronological work in Durango, Mexico, La Paz, Bolivia (both October 2000) and Piura, Peru (January 2001, using IAI-PESCA funding). All will serve regions with little or no prior expertise in tree-ring studies. Dedicated staff are now employed at each facility and have undertaken training at one of the laboratories in the CRN (Mendoza, Tucson, Lamont or Arkansas). The CRN sponsored participation of latin american students in the first dendroecological field courses to be held in Latin America at San Martin de los Andes, Argentina (April 2000); Saltillo, Mexico (August 2001) and in Valdivia, Chile (April 2001).

This project will run in its present form for 5 years and we are still in the initial stages. It will provide new proxy records of local and regional climate variability and change, many from regions that hitherto have been data-poor. It will also be able to generate related datasets (e.g. drought and flow frequencies; estimates of timber production) that may be usefully applied to impact assessment or scenario development for environments undergoing significant climate change. The combination of such regional data sets with other, presently available, data (e.g. from the western United States) will ul- 
timately allow the development of hemispheric-scale datasets for the last 300-500 years. These data sets will be used to document the large spatial and temporal variance that characterises the tropical (ENSO) and high latitude (e.g. PDO) atmospheric circulation features associated with interannual to decadal variability of climate over the Americas. For example, the recent ENSO reconstruction developed by Stahle et al. (1998) may be significantly enhanced by the incorporation of data from drought-resistant and $\mathrm{El}$ Niño sensitive tree-ring chronologies in Central Chile and adjacent Argentina. Similarly the development and combination of data sets to address low frequency climate variability (e.g. Villalba et al, 2001) could significantly improve understanding of phenomena such as the PDO and the relationship between PDO and ENSO phenomena. As the project continues we hope to provide data that will address these large scale issues.

Further information about participating scientists and institutions, plus the first two annual reports of activity and other information can be found on the project's web site at http://www.cricyt.edu.ar/IAl/ or through http://wdc.cricyt.edu.ar/

\section{AcKnowledgements}

We would like to thank R. Villalba, M. Morales and D.W. Stahle for providing the data in Figures 2 and 3, respectively.

\section{REFERENCES}

Acuna-Soto, R., L. Calderon Romero, and J.H. McGuire, 2000. Large epidemics of hemorrhagic fevers in Mexico 1545-1815. American Journal of Tropical Medicine and Hygiene 62(6):733-739.

Acuna-Soto, R., D.W. Stahle, M.K. Cleaveland, M.D. Therrell, in press. Megadrought and megadeath in 16th century Mexico. Emerging Infectious Diseases

Stahle, D.W., D'Arrigo, R.D., Krusic, P.J., Cleaveland M.K., Cook, E.R., Allan, R.J., Cole, J.E., Dunbar, R.B., Therrell, M.D., Gay, D.A., Moore, M.D. Stokes,. M.A., Burns, B,T, Villanueva-Diaz, J. and Thompson, L.G., 1998. Experimental dendroclimatic reconstruction of the southern oscillation. Bulletin of the American Meteorological Society, 79(10): 2137-2152.

Villalba, R., D’Arrigo, R.D., Cook, E.R., Wiles, G, and Jacoby G.C. 2001. Decadal-scale climatic variability along the extratropical western coast of the Americas: Evidences from tree-ring records. In: Inter-Hemispheric Climate Linkages, Vera Markgraf (ed.), Academic Press. pp. 155-172.

\section{Paleoecology of Eastern Africa Mountains}

\section{Daniel 0. Olago and Eric 0. 0dada}

Department of Geology, University of Nairobi, PO Box 30197 Nairobi, Kenya; dolago@uonbi.ac.ke, eodada@uonbi.ac.ke

Africa is a rich repository of paleoenvironmental and paleoclimatic information. It is unique in that it is the only continent that, almost symetrically, straddles the equator, and hence experiences both northern and southern hemispheric climatic influences. This, coupled with the influence of the oceans that surround it, results in an intriguing paleo-record that offers the possibility of understanding the links in climate between the high latitudes and the tropics, and inter-hemispheric teleconnections. Sedimentary records from lakes, swamps and mires, ranging in altitude from sea level to over $5,000 \mathrm{~m}$ above sea level (Kilimanjaro, Ruwenzori and Mt. Kenya, Fig.1), and extending from the northern mid-latitudes to the southern mid-latitudes, provide an array of paleo-proxies and a range of sensitivities to the regional and global climate system that are essential for the elucidation of natural climate and environmental variability in the past. Further data is particularly required in the tropical regions, where a dearth of information exists as compared to the high latitude areas. In particular, most records of the continental tropics do not extend beyond $40,000{ }^{14} \mathrm{C}-\mathrm{yr}$ BP

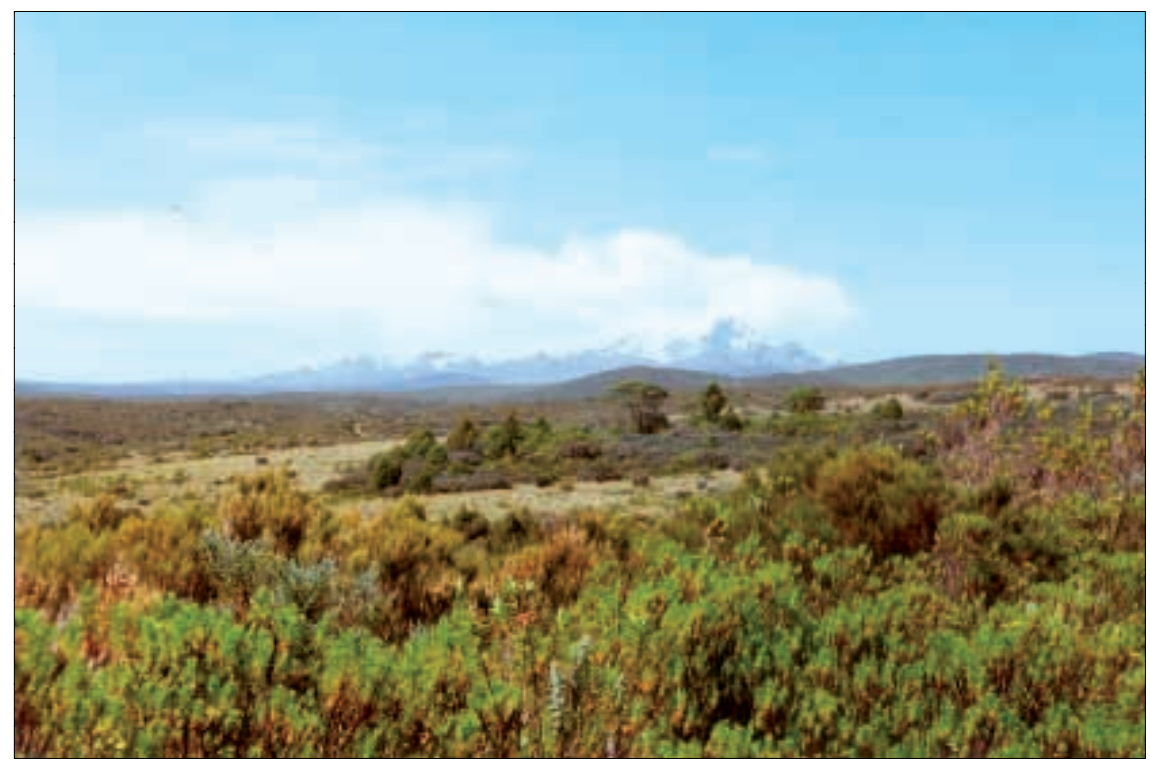

Fig. 1: View of Mount Kenya from the northern moorland.

(most tend to have records less than $\left.30,000{ }^{14} \mathrm{C}-\mathrm{yr} \mathrm{BP}\right)$. In the few cases where a long record exists, poor dating control and consequently poor age models constrain both interpretation, and correlation of events (particularly abrupt events) on local and regional scales.

\section{Modern Vegetation}

The African mountains exhibit high diversity in vegetation types due to the pronounced variations in temperature, atmospheric $\mathrm{CO}_{2}$ con- centration, solar radiation receipts, precipitation and soil moisture indices that are related to the sharp changes in altitude and the effects of topography and aspect. The vegetation is classified into three altitudinal belts, which are, with increasing altitude, the Montane Forest Belt, the Ericaceous Belt and the Afroalpine Belt (Fig. 2). Within the belts, distinct zones are recognised: thus, the Montane Forest Belt contains, in ascending order, the Montane Rain Forest Zone, the Bamboo Zone 